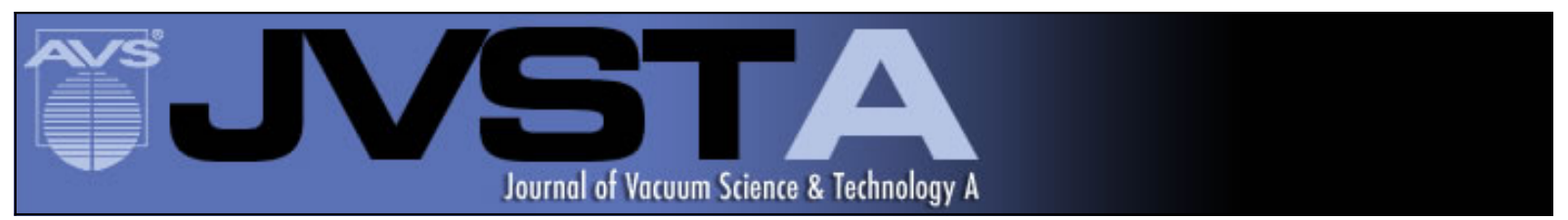

\title{
Al capping layers for nondestructive x-ray photoelectron spectroscopy analyses of transition-metal nitride thin films
}

Grzegorz Greczynski, Ivan Petrov, J. E. Greene, and Lars Hultman

Citation: Journal of Vacuum Science \& Technology A 33, 05E101 (2015); doi: 10.1116/1.4916239

View online: http://dx.doi.org/10.1116/1.4916239

View Table of Contents: http://scitation.aip.org/content/avs/journal/jvsta/33/5?ver=pdfcov

Published by the AVS: Science \& Technology of Materials, Interfaces, and Processing

\section{Articles you may be interested in}

X-ray Photoelectron Spectroscopy Analyses of the Electronic Structure of Polycrystalline Ti1-xAlxN Thin Films with $0 \leq x \leq 0.96$

Surf. Sci. Spectra 21, 35 (2014); 10.1116/11.20140506

Erratum: "X-ray photoelectron spectroscopy study of irradiation-induced amorphization of Gd 2 Ti 2 O 7 " [Appl. Phy. Lett. 79, 1989 (2001)]

Appl. Phys. Lett. 80, 3650 (2002); 10.1063/1.1472474

X-ray photoelectron spectroscopy study of irradiation-induced amorphizaton of Gd 2 Ti 207

Appl. Phys. Lett. 79, 1989 (2001); 10.1063/1.1402647

In situ X-ray Photoelectron, Ultraviolet Photoelectron, and Auger Electron Spectroscopy Spectra from First-Row Transition-Metal Nitrides: ScN, TiN, VN, and CrN

Surf. Sci. Spectra 7, 167 (2000); 10.1116/1.1360984

X-ray photoelectron spectroscopy analyses of metal stacks etched in $\mathrm{Cl} 2$ / $\mathrm{BCl} 3$ high density plasmas

J. Vac. Sci. Technol. B 16, 147 (1998); 10.1116/1.589770

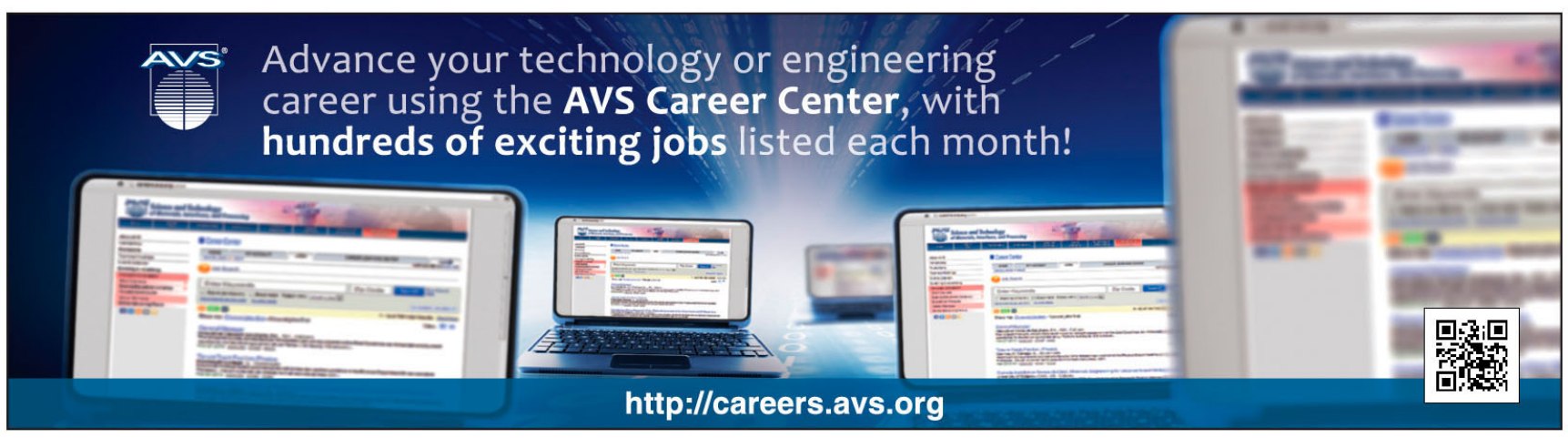




\title{
Al capping layers for nondestructive $x$-ray photoelectron spectroscopy analyses of transition-metal nitride thin films
}

\author{
Grzegorz Greczynskia) \\ Thin Film Physics Division, Department of Physics (IFM), Linköping University, SE-581 83 Linköping, \\ Sweden \\ Ivan Petrov \\ Thin Film Physics Division, Department of Physics (IFM), Linköping University, SE-581 83 Linköping, \\ Sweden and Materials Science Department and Frederick Seitz Materials Research Laboratory, \\ University of Illinois, Urbana, Illinois 61801 \\ J. E. Greene \\ Thin Film Physics Division, Department of Physics (IFM), Linköping University, SE-581 83 Linköping, \\ Sweden; Materials Science Department and Frederick Seitz Materials Research Laboratory, \\ University of Illinois, Urbana, Illinois 61801; and Department of Physics, University of Illinois, \\ Urbana, Illinois 61801 \\ Lars Hultman \\ Thin Film Physics Division, Department of Physics (IFM), Linköping University, SE-581 83 Linköping, \\ Sweden
}

(Received 28 January 2015; accepted 16 March 2015; published 30 March 2015)

\begin{abstract}
X-ray photoelectron spectroscopy (XPS) compositional analyses of materials that have been air exposed typically require ion etching in order to remove contaminated surface layers. However, the etching step can lead to changes in sample surface and near-surface compositions due to preferential elemental sputter ejection and forward recoil implantation; this is a particular problem for metal/gas compounds and alloys such as nitrides and oxides. Here, the authors use TiN as a model system and compare XPS analysis results from three sets of polycrystalline $\mathrm{TiN} / \mathrm{Si}(001)$ films deposited by reactive magnetron sputtering in a separate vacuum chamber. The films are either (1) air-exposed for $\leq 10 \mathrm{~min}$ prior to insertion into the ultrahigh-vacuum (UHV) XPS system; (2) air-exposed and subject to ion etching, using different ion energies and beam incidence angles, in the XPS chamber prior to analysis; or (3) Al-capped in-situ in the deposition system prior to air-exposure and loading into the XPS instrument. The authors show that thin, $1.5-6.0 \mathrm{~nm}, \mathrm{Al}$ capping layers provide effective barriers to oxidation and contamination of TiN surfaces, thus allowing nondestructive acquisition of high-resolution core-level spectra representative of clean samples, and, hence, correct bonding assignments. The Ti $2 \mathrm{p}$ and $\mathrm{N}$ 1s satellite features, which are sensitive to ion bombardment, exhibit high intensities comparable to those obtained from single-crystal TiN/MgO(001) films grown and analyzed in-situ in a UHV XPS system and there is no indication of $\mathrm{Al} / \mathrm{TiN}$ interfacial reactions. XPS-determined $\mathrm{N} / \mathrm{Ti}$ concentrations acquired from $\mathrm{Al} / \mathrm{TiN}$ samples agree very well with Rutherford backscattering and elastic recoil analysis results while ion-etched air-exposed samples exhibit strong $\mathrm{N}$ loss due to preferential resputtering. The intensities and shapes of the Ti $2 \mathrm{p}$ and $\mathrm{N} 1$ s core level signals from $\mathrm{Al} / \mathrm{TiN} / \mathrm{Si}(001)$ samples do not change following long-term (up to 70 days) exposure to ambient conditions, indicating that the thin Al capping layers provide stable surface passivation without spallation. (ㅇ 2015 American Vacuum Society. [http://dx.doi.org/10.1116/1.4916239]
\end{abstract}

\section{INTRODUCTION}

Refractory ceramic transition-metal (TM) nitride thin films grown by physical vapor deposition attract increasing scientific and technological interest due to their unique properties combining high hardness, ${ }^{1-4}$ good high-temperature oxidation resistance, ${ }^{5-7}$ electrical conductivity ranging from metallic to semiconducting, ${ }^{8,9}$ superconductivity, ${ }^{9-11}$ and optical absorption, which can be tuned across the visible spectrum. ${ }^{8}$ Applications include wear-resistant coatings on high-speed cutting tools ${ }^{12,13}$ and engine components, ${ }^{14,15}$

${ }^{\text {a)} E l e c t r o n i c ~ m a i l: ~ g r z g r @ i f m . l i u . s e ~}$ diffusion barriers in electronic devices, ${ }^{16-20}$ and bioimplant coatings. ${ }^{21} \mathrm{NaCl}$-structure TM nitride thin films also have wide single-phase fields, which support large vacancy concentrations on the anion sublattice, resulting in the case of $\mathrm{TiN},{ }^{22}$ in N/Ti ratios which range from 0.6 to $1.0,{ }^{23}$ allowing room-temperature resistivity of epitaxial $\mathrm{TiN}(001)$ layers to be controllably varied from 13 to $190 \mu \Omega \mathrm{cm}$ (Ref. 24) and the hardness from 20 to $30 \mathrm{GPa}$ (Ref. 4) as N/Ti is decreased from 1.0 to 0.6 .

X-ray photoelectron spectroscopy (XPS) is often used to provide not only compositional analyses of TM-nitridebased pseudobinary, ternary, and higher-order thin film alloys developed for specific applications, but also to acquire 
detailed information regarding elemental bonding configurations. TM nitride films are typically grown by magnetron sputter deposition in vacuum systems that do not contain insitu XPS capability; the films are then air-exposed prior to inserting them into a stand-alone XPS system. Ion etching is used to remove oxygen and other adventitious surface contamination prior to analysis. However, the etching process can lead to preferential elemental sputter ejection, recoil implantation, and structural disorder, all of which render quantitative compositional and chemical analyses extremely challenging. ${ }^{25}$

In order to circumvent these problems, capping layers have been used to protect the sample surface from air exposure during transport to the XPS instrument. For example, Kramer et al. passivated surfaces of metastable (III-IV $)_{1-x}\left(\mathrm{IV}_{2}\right)_{x}$ semiconducting films with As, which was then desorbed in-situ prior to XPS analysis. ${ }^{26,27}$ Thin capping layers $(\$ 10 \mathrm{~nm})$ were also used to allow direct XPS verification of barrier integrity and check for cap-layer/sample-surface reactions. ${ }^{28}$

Here, we investigate the effectiveness of metal capping layers for nondestructive high-resolution XPS analyses of ceramic thin films. We use, as a model materials system, polycrystalline 200-nm-thick NaCl-crystal structure TiN layers grown on $\mathrm{Si}(001)$ substrates at $400^{\circ} \mathrm{C}$ by reactive magnetron sputter deposition in mixed $\mathrm{N}_{2} / \mathrm{Ar}$ atmospheres. The cap layer thickness is optimized such that high-quality XPS spectra of the underlying TiN surface can be obtained without significant attenuation. We select $\mathrm{Al}$ as the cap layer for the following reasons: (1) the Al native oxide, $<2 \mathrm{~nm}$ thick at room temperature, is stable against spallation; ${ }^{5}$ (2) the $\mathrm{Al}-\mathrm{N}$ heat of formation $\left(\Delta_{f} H_{\mathrm{AlN}}^{0}=-3.3 \mathrm{eV} / \mathrm{atom}\right)$ is lower than that of $\mathrm{Ti}-\mathrm{N}\left(\Delta_{f} H_{\mathrm{TiN}}^{0}=-3.5 \mathrm{eV} /\right.$ atom $),{ }^{29}$ thus minimizing interfacial reactions; (3) and $\mathrm{Al}$ core-level peaks do not overlap with the primary $\mathrm{Ti}$ and $\mathrm{N}$ signals. We show that $\mathrm{Al}$ layers with thickness $d_{\mathrm{Al}}=1.5 \mathrm{~nm}$ form a dense continuous, oxidized barrier that protects the TiN underlayer and allows for acquisition of high-resolution $\mathrm{Ti} 2 \mathrm{p}$ and $\mathrm{N} 1 \mathrm{~s}$ core-level spectra, with clear pronounced satellite features, ${ }^{30-33}$ which are in excellent agreement with those obtained from epitaxial TiN layers grown in-situ in an XPS system. ${ }^{34} \mathrm{O} 1 \mathrm{~s}$ spectra reveal no evidence for Ti-O bonding. High-resolution Al 2p scans from 1.5-nm-Al/TiN/Si(001) samples indicate that the entire cap layer is oxidized with no $\mathrm{Al} / \mathrm{TiN}$ interfacial reactions. In addition, XPS-determined $\mathrm{N} / \mathrm{Ti}$ compositional ratios, obtained based upon Ti $2 \mathrm{p}$ and $\mathrm{N}$ $1 \mathrm{~s}$ peak areas, agree very well with the results of Rutherford backscattering spectroscopy (RBS) and time-of-flight elastic recoil detection analyses (ToF-ERDA).

\section{EXPERIMENTAL PROCEDURE}

Polycrystalline $\mathrm{TiN} / \mathrm{Si}(001)$ layers, as well as $\mathrm{Al}$ cap layers, are grown in a CemeCon CC800/9 magnetron sputtering system. The targets are cast rectangular $8.8 \times 50 \mathrm{~cm}^{2}$ $\mathrm{Ti}$ and $\mathrm{Al}$ plates (99.99\% pure). Shutters are used to protect one target while sputter etching the other, immediately prior to film growth, in order to avoid cross-contamination.
$\mathrm{Si}(001)$ substrates, $1.5 \times 1 \mathrm{~cm}^{2}$, are cleaned sequentially in acetone and isopropyl alcohol and mounted on a rotary substrate table at a distance of six $\mathrm{cm}$ from the target. The system is degassed prior to deposition using a two-step heating cycle: $1 \mathrm{~h}$ at $500^{\circ} \mathrm{C}$ followed by $1 \mathrm{~h}$ during which the temperature is slowly decreased to $400{ }^{\circ} \mathrm{C}$, the deposition temperature $T_{s}$. TiN layers, 200-nm thick, are grown in mixed $\mathrm{Ar} / \mathrm{N}_{2}$ atmospheres at a total pressure $P_{\mathrm{tot}}=3 \mathrm{mTorr}$ (0.4 Pa). Ar and $\mathrm{N}_{2}$ flow rates are $f_{\mathrm{Ar}}=350 \mathrm{~cm}^{3} / \mathrm{min}$ and $f_{\mathrm{N} 2}=50 \mathrm{~cm}^{3} / \mathrm{min}$.

The Ti target is operated in high-power pulsed magnetron sputtering mode at an average power of $1300 \mathrm{~W}$, a pulsing frequency of $1000 \mathrm{~Hz}$, and a duty cycle of $20 \%$. A substrate bias voltage $V_{s}=60 \mathrm{~V}$ is applied in synchronous with the target pulses. ${ }^{35-39}$ Following TiN deposition, $f_{\mathrm{N} 2}$ is set to zero while $f_{\mathrm{Ar}}$ is increased to $400 \mathrm{~cm}^{3} / \mathrm{min}$ to maintain $P_{\text {tot }}$ constant; the Al target is sputter-cleaned for $60 \mathrm{~s}$ with both target shutters closed, and the $\mathrm{TiN} / \mathrm{Si}(001)$ samples are rotated in front of the $\mathrm{Al}$ target, which is operated at $0.3 \mathrm{~kW}$ $\mathrm{dc}$ power for cap-layer deposition. Al overlayers are deposited with thicknesses ranging from 1.5 to $25 \mathrm{~nm}$, based upon deposition rate calibrations. For reference, we also deposit $2-\mu \mathrm{m}$-thick $\mathrm{Al}$ films on $\mathrm{TiN} / \mathrm{Si}(001)$ samples.

RBS analyses, using a $2.0 \mathrm{MeV}{ }^{4} \mathrm{He}^{+}$probe beam incident at $10^{\circ}$ with respect to the surface normal and detected at a $172^{\circ}$ scattering angle, as well as ToF-ERDA measurements employing a $36 \mathrm{MeV}{ }^{127} \mathrm{I}^{8+}$ probe beam incident at $67.5^{\circ}$ with recoils detected at $45^{\circ}$, show that the TiN films are slightly understoichiometric with $\mathrm{N} / \mathrm{Ti}=0.96 \pm 0.01$. Film thicknesses determined from cross-sectional scanning electron microscopy analyses in a LEO 1550 instrument are in good agreement with deposition-rate calibrations.

$\mathrm{X}$-ray diffraction $\theta-2 \theta$ scans and pole figure measurements show that the TiN films are single-phase with the cubic $\mathrm{B} 1 \mathrm{NaCl}$ structure. The layers are polycrystalline with random in-plane orientation and no strong out-of-plane orientation.

XPS spectra are acquired from air-exposed TiN and $\mathrm{Al} / \mathrm{TiN}$ films in a Kratos Analytical instrument, with a base pressure of $1.1 \times 10^{-9} \mathrm{Torr}\left(1.5 \times 10^{-7} \mathrm{~Pa}\right)$, using monochromatic $\mathrm{Al} \mathrm{K} \alpha$ radiation $(\mathrm{h} \nu=1486.6 \mathrm{eV})$ with the $\mathrm{x}$-ray anode operated at $225 \mathrm{~W}$. The signal is detected orthogonal to the sample surface. The Fermi edge cut-off is set, using sputteretched clean Ag foil, to an accuracy of better than $\pm 0.05 \mathrm{eV}$ and the position of the $\mathrm{Ag} 3 \mathrm{~d}_{5 / 2}$ core-level peak is verified to be $368.30 \mathrm{eV}^{40}$ All core-level (narrow energy range) spectra are acquired with a pass energy $E_{\text {pass }}=20 \mathrm{eV}$. For the $\mathrm{Ag}$ $3 \mathrm{~d}_{5 / 2}$ reference peak, this results in a full-width at half maximum FWHM peak intensity of $0.55 \mathrm{eV}$. For survey (wide energy range) scans, $E_{\text {pass }}=160 \mathrm{eV}$ resulting in a $\mathrm{Ag} 3 \mathrm{~d}_{5 / 2}$ FWHM of $2.00 \mathrm{eV}$. Quantification is performed using CASAXPS software (version 2.3.16), based upon peak areas from narrow energy range scans with the Shirley-type background removed. ${ }^{41}$ Elemental sensitivity factors, corrected for (1) the energy-dependent transmission function of the spectrometer, and (2) the effect of kinetic-energy-dependent electron mean free paths, are supplied by Kratos Analytical Ltd. $^{42}$ 
Al-capped and uncapped TiN/Si(001) films are exposed to air for $\leq 10 \mathrm{~min}$ during transport from the deposition chamber to the XPS system where they are analyzed without further processing. A second set of uncapped TiN samples is subjected to sputter-etching in the XPS instrument prior to analysis using an $\mathrm{Ar}$ ion beam with (a) an ion energy $E_{\mathrm{Ar}^{+}}=0.5 \mathrm{keV}$ and a beam incidence angle of $\psi=70^{\circ}$ relative to the surface normal; (b) $E_{\mathrm{Ar}^{+}}=4 \mathrm{keV}$ with $\psi=70^{\circ}$; (c) $E_{\mathrm{Ar}^{+}}=4 \mathrm{keV}, \psi=45^{\circ}$; and (d) $E_{\mathrm{Ar}^{+}}=4 \mathrm{keV}, \psi=0^{\circ}$. In all cases, XPS spectra are obtained from a $0.3 \times 0.7 \mathrm{~mm}^{2}$ area at the center of the sputter-etched region after removal of $\sim 10 \mathrm{~nm}$.

Transport of ions in matter (TRIM), ${ }^{43}$ a Monte Carlo program included in the stopping power and range of ions in matter (SRIM) software package, ${ }^{44}$ is used to estimate primary-ion and recoil projected ranges in TiN due to $\mathrm{Ar}$ ion irradiation during sputter etching.

\section{RESULTS}

\section{A. XPS analyses of $\mathrm{Ar}^{+}$-ion-etched air-exposed $\mathrm{TiN} / \mathrm{Si}(001)$}

Typical Ti $2 p$ and N 1s core-level spectra acquired from sputter-etched uncapped air-exposed TiN surfaces are shown in Figs. 1(a) and 1(b) for the four sets of $E_{\mathrm{Ar}^{+}} / \psi$ etching conditions. The Ti $2 p$ core-level spectra consist of a spin-orbit split doublet with Ti $2 \mathrm{p}_{3 / 2}$ and Ti $2 \mathrm{p}_{1 / 2}$ components at 455.2 and $461.1 \mathrm{eV}$, respectively. Both Ti $2 \mathrm{p}$ peaks exhibit satellite features on the high binding-energy (BE) side, shifted $\sim 2.7 \mathrm{eV}$ above the primary peaks, in agreement with previous XPS analyses of polycrystalline TiN layers grown in-situ in an XPS system. ${ }^{45,46}$ To facilitate comparison, the intensities of $\mathrm{Ti} 2 \mathrm{p}$ spectra are normalized to those of the highest intensity features $\left(\mathrm{Ti} 2 \mathrm{p}_{3 / 2}\right.$ at $455.2 \mathrm{eV}$, after subtraction of the low-BE background) for each spectrum. The same scale factors are then used to normalize the corresponding $\mathrm{N}$ 1s spectra in Fig. 1(b). The relative intensities of the satellite peaks [see inset in Fig. 1(a)] are highest after sputter etching with $E_{\mathrm{Ar}^{+}}=0.5 \mathrm{keV}$ and $\psi=70^{\circ}$; they decrease in intensity upon increasing $E_{\mathrm{Ar}^{+}}$to $4 \mathrm{keV}$ (at $\psi=70^{\circ}$ ); and decrease even further as $\psi$ is lowered to $45^{\circ}$ and $0^{\circ}$, while maintaining $E_{\mathrm{Ar}^{+}}$at $4 \mathrm{keV}$. The reduction in the satellite feature intensity due to ion etching is accompanied by increasing background levels on the high $\mathrm{BE}$ side. The origin of $\mathrm{Ti} 2 \mathrm{p}$ satellite features from $\mathrm{TiN}_{\mathrm{x}}$ films with $x>0.75$ (Ref. 30 ) is widely discussed in the literature. Two primary interpretations have been proposed including a decrease in the screening probability of the core-hole created during photoionization by Ti $3 \mathrm{~d}$ electrons, ${ }^{30,32,45}$ and $\mathrm{t}_{1 \mathrm{~g}} \rightarrow$ $2 \mathrm{t}_{2 \mathrm{~g}}$ intraband transitions between occupied and unoccupied electron states near the Fermi level (shake-up events). ${ }^{31,47}$ The intensity of the Ti $2 p$ satellite features has also been shown to be sensitive to changes induced by Ar ion bombardment (residual point-defect creation, grain refinement, atomic mixing, Ar trapping in interstitial sites, and $\mathrm{N}$ loss due to preferential resputtering of lighter elements) as demonstrated by Haasch et al. ${ }^{48}$ for epitaxial TiN/MgO(001) films grown in-situ, with no air exposure, in an XPS system
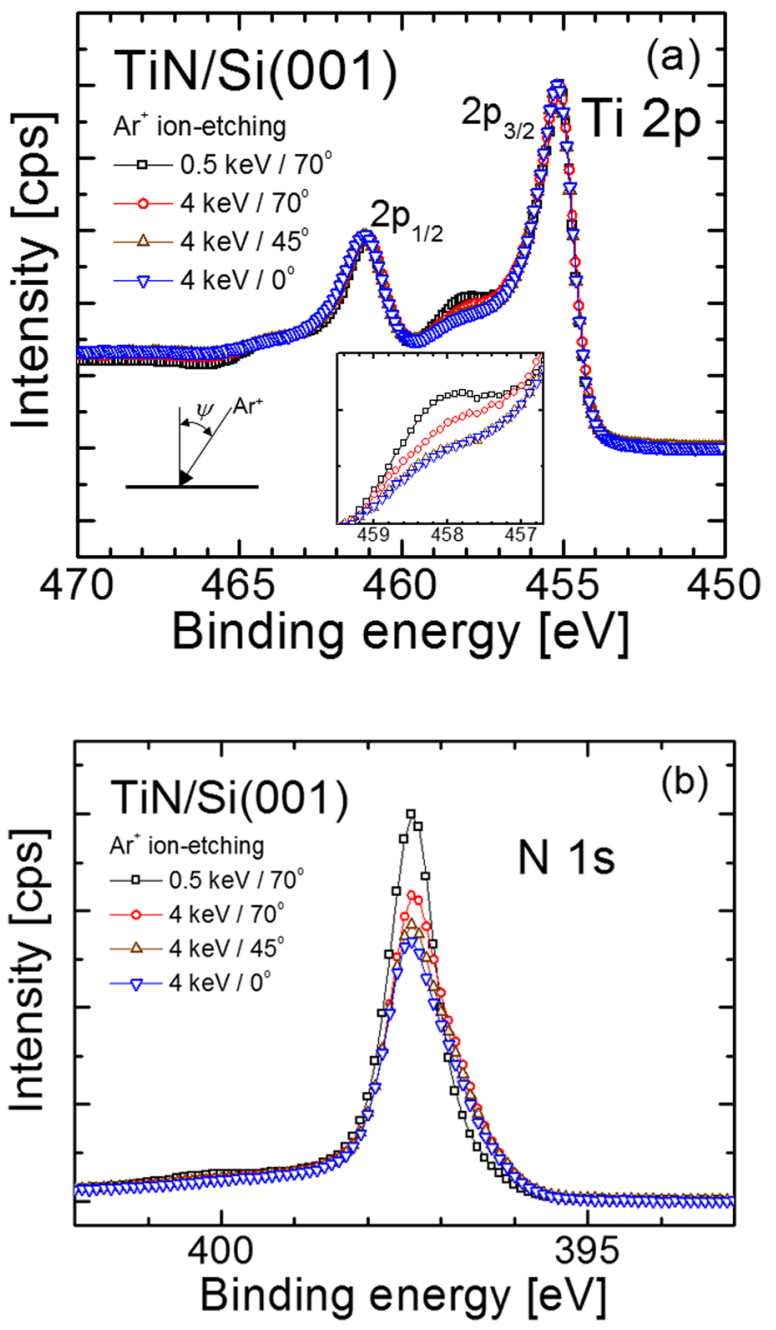

FIG. 1. (Color online) (a) XPS Ti 2p and (b) N 1s core-level spectra acquired from sputter-etched uncapped air-exposed polycrystalline $\mathrm{TiN} / \mathrm{Si}(001)$ surfaces. The etching conditions are $E_{\mathrm{Ar}^{+}}=0.5 \mathrm{keV} / \psi=70^{\circ}, 4 \mathrm{keV} / 70^{\circ}$, $4 \mathrm{keV} / 45^{\circ}$, and $4 \mathrm{keV} / 0^{\circ}$.

and then ion-etched with a $3 \mathrm{keV} \mathrm{Ar}$ ion beam incident at $\psi=40^{\circ}$. Thus, the changes in Ti $2 \mathrm{p}$ spectra shown in Fig. 1(a) are indicative of ion-irradiation-induced compositional and structural modifications, which increase with increasing $\mathrm{Ar}^{+}$ion penetration depth $\xi$.

The N 1s core-level peak at $397.4 \mathrm{eV}$, Fig. 1(b), is also affected by ion irradiation. The peak intensity decreases, accompanied by peak broadening toward the lower BE side, with increasing ion energy $E_{\mathrm{Ar}^{+}}$and decreasing ion incidence angle $\psi$. The satellite feature at $\sim 400.2 \mathrm{eV}$ has a lower intensity than the Ti $2 p$ satellites [see Fig. 1(a)], but exhibits a similar shift to higher $\mathrm{BE}$ with respect to the $\mathrm{N}$ 1s peak and decreases in intensity with increasing $E_{\mathrm{Ar}^{+}}$and decreasing $\psi$, i.e., increasing $\xi$. In addition, the XPS-determined N/Ti ratio decreases from $0.74 \pm 0.03$ with $E_{\mathrm{Ar}^{+}}=0.5 \mathrm{keV}$ and $\psi=70^{\circ}$, to $0.72 \pm 0.03,0.70 \pm 0.03$, and $0.68 \pm 0.03$ with $E_{\mathrm{Ar}^{+}}=4 \mathrm{keV}$ and $\psi=70^{\circ}, 45^{\circ}$, and $0^{\circ}$, indicating preferential $\mathrm{N}$ loss, in agreement with previous reports. ${ }^{48}$

The above results clearly illustrate issues associated with XPS analyses following ion etching of air-exposed TiN surfaces. Both Ti $2 p$ and $\mathrm{N}$ 1s core-level spectra are sensitive 
to increased residual ion-irradiation-induced damage. The effects are least visible for the lowest $E_{\mathrm{Ar}^{+}}$and highest $\psi$ values used in these experiments. However, even for this case, the uncapped TiN samples exhibit significant preferential $\mathrm{N}$ loss due to resputtering.

\section{B. XPS analyses of Al-capped TiN/Si(001)}

Figures 2(a)-2(d) are typical SEM plan-view images of $\mathrm{Al} / \mathrm{TiN} / \mathrm{Si}(001)$ samples with $\mathrm{Al}$ cap layer thicknesses $d_{\mathrm{Al}}$ ranging from 1.5 to $25 \mathrm{~nm}$. The surface of the sample with the thinnest capping layer is relatively featureless and closely resembles that of the uncapped TiN film (not shown). With increasing $d_{\mathrm{Al}}$, the average feature size increases from $<10 \mathrm{~nm}$ with $d_{\mathrm{Al}}=1.5 \mathrm{~nm}$ to $20 \pm 10,45 \pm 15$, and $90 \pm 20 \mathrm{~nm}$ with $d_{\mathrm{Al}}=6.0,13.5$, and $25.0 \mathrm{~nm}$.

Figures 3(a)-3(d) are Ti 2p, N 1s, Al 2p, and O 1s corelevel spectra acquired from a series of $\mathrm{TiN} / \mathrm{Si}(001)$ samples, which were either uncapped or capped with Al layers with thicknesses $d_{\mathrm{Al}}$ from 1.5 to $25 \mathrm{~nm}$ prior to air exposure. Samples used for this set of spectra are analyzed as-received and not $\mathrm{Ar}^{+}$-ion etched.

The core level spectra from $\mathrm{TiN} / \mathrm{Si}(001)$ samples with no Al overlayer exhibit pronounced effects of air exposure; the $\mathrm{Ti} 2 \mathrm{p}$ spectrum in Fig. 3(a) shows that Ti is present in three chemical states: $\mathrm{TiN}, \mathrm{TiO}_{\mathrm{x}} \mathrm{N}_{\mathrm{y}}$, and Ti-oxide giving rise to $\mathrm{Ti}$ $2 \mathrm{p}_{3 / 2}$ peaks at $455.2,456.7$, and $458.2 \mathrm{eV}$, respectively. ${ }^{49,50}$ The corresponding N 1s spectrum [Fig. 3(b)] also contains three peaks: $\mathrm{TiN}$ at $397.4 \mathrm{eV},{ }^{50,51} \mathrm{TiO}_{\mathrm{x}} \mathrm{N}_{\mathrm{y}}$ at $396.1 \mathrm{eV},{ }^{49}$ and a low-intensity TiN satellite at $\sim 400.2 \mathrm{eV}$, while the $\mathrm{O} 1 \mathrm{~s}$ spectrum [Fig. 3(d)] consists of two peaks at 529.9 and $531.4 \mathrm{eV}$ attributed to oxygen in Ti-oxide and $\mathrm{TiO}_{\mathrm{x}} \mathrm{N}_{\mathrm{y}}$ bonding configurations, respectively. ${ }^{49,50}$ Thus, the Ti $2 \mathrm{p}, \mathrm{N} 1 \mathrm{~s}$, and $\mathrm{O} 1 \mathrm{~s}$ spectra are consistent in indicating the presence of Ti-oxide and $\mathrm{TiO}_{\mathrm{x}} \mathrm{N}_{\mathrm{y}}$ due to air exposure.

In distinct contrast, spectra recorded from TiN films with $\mathrm{Al}$ cap layers exhibit no indication of Ti-oxide or
Ti-oxynitride formation. Ti $2 \mathrm{p}$ and $\mathrm{N}$ 1s core-level signals, Figs. 3(a) and 3(b), resemble those acquired from epitaxial $\mathrm{TiN} / \mathrm{MgO}(001)$ layers grown in-situ in an XPS system, and analyzed with no air-exposure or $\mathrm{Ar}^{+}$ion etching. ${ }^{48}$ The $\mathrm{O}$ $1 \mathrm{~s}$ spectrum, Fig. 3(d), consists of only a single peak at $532.0 \mathrm{eV}$, shifted toward higher $\mathrm{BE}$ with respect to the uncapped sample, corresponding to $\mathrm{Al}-\mathrm{O}$ bonding in Al-oxide. The Al $2 p$ spectra in Fig. 3(c) reveals that the 1.5-nm-thick $\mathrm{Al}$ cap layers are fully oxidized with an oxide peak at $75.1 \mathrm{eV}$ and no observable contribution due to metallic $\mathrm{Al}^{40}$

With increasing $\mathrm{Al}$ capping layer thickness $d_{\mathrm{Al}}$, the Ti $2 \mathrm{p}$ and $\mathrm{N}$ 1s peak intensities decrease due to inelastic electron scattering in the overlayer, as discussed further in Sec. IV. There are no detectable Ti $2 \mathrm{p}$ or N 1s peak shifts or shape changes. The $\mathrm{O} 1 \mathrm{~s}$ peak increases and shifts slightly from 532.0 to $532.4 \mathrm{eV}$, due to charging in the Al-oxide layer, characteristic of native $\mathrm{Al}$ oxide formation as observed for the $2-\mu \mathrm{m}$-thick $\mathrm{Al}$ reference layer. The $\mathrm{Al} 2 \mathrm{p}$ spectra in Fig. 3(c) exhibit only a single broad peak at $75.1 \mathrm{eV}$ corresponding to native $\mathrm{Al}$ oxide. ${ }^{50}$ The $\mathrm{Al} 2 \mathrm{p}$ spectra from samples with $d_{\mathrm{Al}} \geq 6.0 \mathrm{~nm}$ contain, in addition to the $\mathrm{Al}-\mathrm{O}$ peak, a metallic Al peak at $72.9 \mathrm{eV},{ }^{40}$ which increases in intensity with increasing $\mathrm{Al}$ layer thickness. For samples with $d_{\mathrm{Al}}=25 \mathrm{~nm}$, the $\mathrm{Al} 2 \mathrm{p}$ spectra is essentially identical to that acquired from the $2-\mu \mathrm{m}$-thick $\mathrm{Al}$ reference layer. The metallic peak has a much lower FWHM allowing spin-orbit splitting $(\Delta \mathrm{E}=0.4 \mathrm{eV})$ to be resolved with $\mathrm{Al} 2 \mathrm{p}_{3 / 2}=72.8 \mathrm{eV}$ and $\mathrm{Al} 2 \mathrm{p}_{1 / 2}=73.2 \mathrm{eV}$. The $\mathrm{BE}$ of the Al-oxide peak increases slightly to $75.5 \pm 0.1 \mathrm{eV}$ for samples with cap layer thickness $d_{\mathrm{Al}}=13.5$ and $25.0 \mathrm{~nm}$. There is no evidence of AlN formation, which would lead to a peak at $74.2 \mathrm{eV},{ }^{33}$ in the $\mathrm{Al} 2 \mathrm{p}$ spectra.

The Ti $2 \mathrm{p}$ and $\mathrm{N}$ 1s spectra in Figs. 4(a) and 4(b), from uncapped $\mathrm{TiN} / \mathrm{Si}(001)$ samples ion-etched with $E_{\mathrm{Ar}^{+}}=0.5 \mathrm{keV}$ and $\psi=70^{\circ}$ (the conditions resulting in the
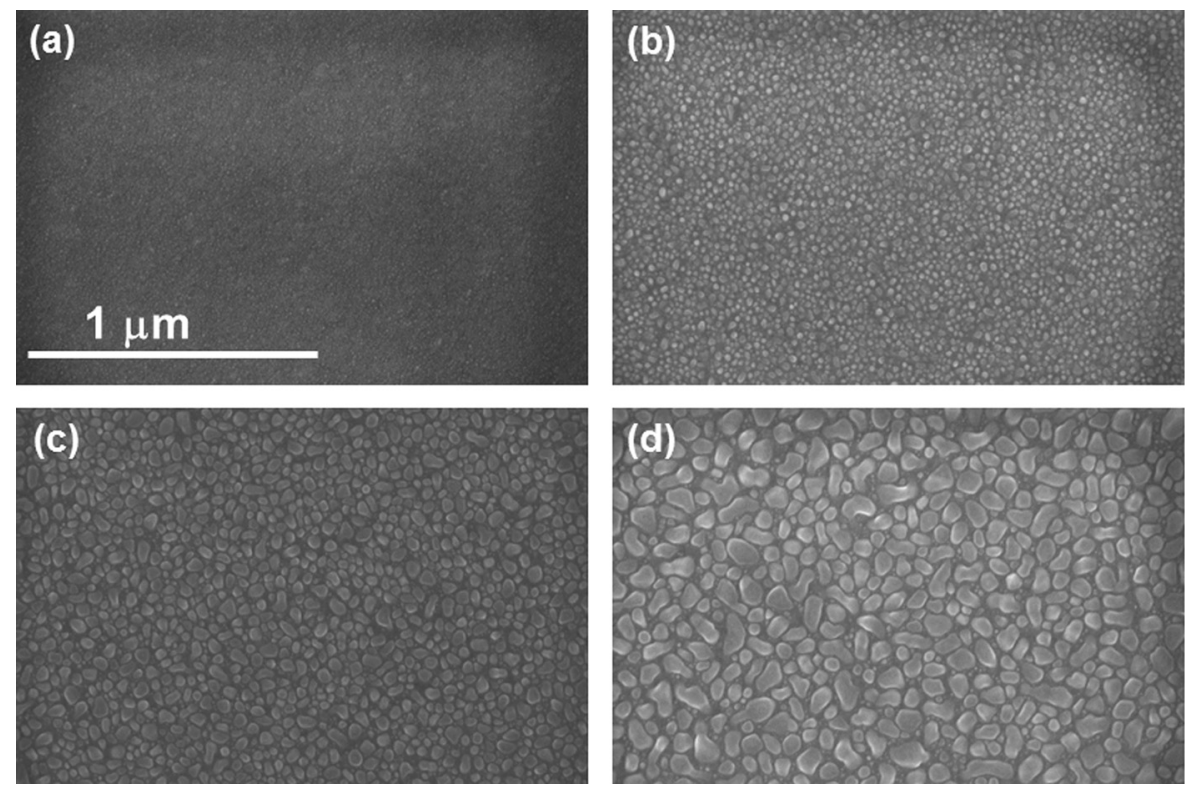

FIG. 2. SEM plan-view images of polycrystalline $\mathrm{Al} / \mathrm{TiN} / \mathrm{Si}(001)$ films with $\mathrm{Al}$ cap layer thicknesses $d_{\mathrm{Al}}$ of: (a) 1.5 , (b) 6.0 , (c) 13.5 , and (d) $25.0 \mathrm{~nm}$. 

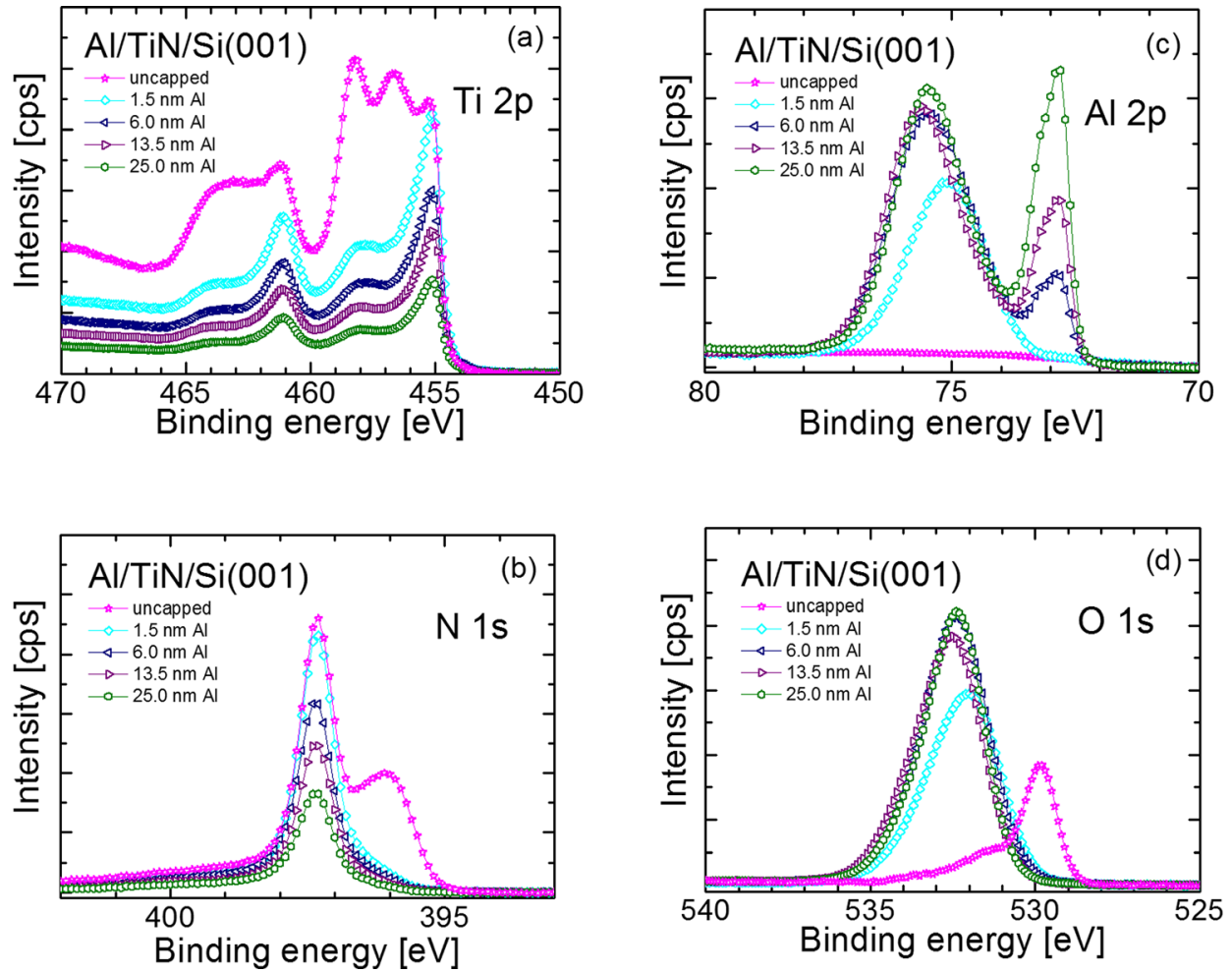

FIG. 3. (Color online) XPS (a) Ti 2p, (b) N 1s, (c) Al 2p, and (d) O 1s core-level spectra acquired from a series of air-exposed polycrystalline TiN/Si(001) films, which were uncapped and capped with $\mathrm{Al}$ overlayers of thickness $d_{\mathrm{Al}}=1.5,6.0,13.5$, and $25.0 \mathrm{~nm}$ prior to air exposure. The samples were analyzed as received with no $\mathrm{Ar}^{+}$ion etching.

least sample damage) are directly compared with those obtained from air-exposed, but unetched, $\mathrm{Al} / \mathrm{TiN} / \mathrm{Si}(001)$ samples with 1.5-nm-thick Al cap layers. To facilitate comparison, Ti $2 \mathrm{p}_{3 / 2}$ Ti-N bonding peaks at $455.2 \mathrm{eV}$ are normalized in the manner described earlier. The same scaling factors are then used to normalize the corresponding $\mathrm{N} 1 \mathrm{~s}$ spectra in order to illustrate differences in XPS-determined $\mathrm{N} / \mathrm{Ti}$ ratios.

The Ti $2 p$ satellite intensity obtained from the Al-capped sample is higher than for all $\mathrm{Ar}^{+}$ion-etched surfaces and comparable to that acquired from epitaxial TiN/MgO(001) films grown in-situ in an XPS system with no air exposure. ${ }^{34}$ The increase in the background intensities on the high-BE sides of the Ti $2 p$ peaks from the capped sample in Fig. 4(a), due to inelastic electron scattering in the $\mathrm{Al}$ overlayer, is very small and does not degrade the primary peak signals.

The intensity of the $\mathrm{N} 1 \mathrm{~s}$ Ti-N peak obtained from the 1.5-nm $\mathrm{Al} / \mathrm{TiN} / \mathrm{Si}(001)$ sample, Fig. 4(b), is much higher than that of all uncapped TiN samples, even those subjected to the mildest etching conditions $\left(E_{\mathrm{Ar}^{+}}=0.5 \mathrm{keV}\right.$ and $\psi=70^{\circ}$ ) for which the XPS-determined $\mathrm{N} / \mathrm{Ti}$ ratio is $0.74 \pm 0.03$. The $\mathrm{N} / \mathrm{Ti}$ ratio obtained from the Al-capped TiN sample is $0.98 \pm 0.03$, in good agreement with RBS and ToF-ERDA results of $0.96 \pm 0.01$. The inset in Fig. 4(b) shows normalized $\mathrm{N}$ 1s spectra for uncapped $\mathrm{TiN} / \mathrm{Si}(001)$ samples ion-etched with $E_{\mathrm{Ar}^{+}}=0.5 \mathrm{keV} / \psi=70^{\circ}$ together with air-exposed, but unetched, $\mathrm{Al} / \mathrm{TiN} / \mathrm{Si}(001)$ samples with 1.5-nm-thick Al cap layers. The shape of the $\mathrm{N} 1 \mathrm{~s}$ spectra acquired from TiN samples with $\mathrm{Al}$ capping layers is very similar to that of the air-exposed uncapped $\mathrm{TiN} / \mathrm{Si}(001)$ film ion etched with $E_{\mathrm{Ar}^{+}}=0.5 \mathrm{keV}$ and $\psi=70^{\circ}$, with the higher BE N 1s satellite peak at $\sim 400.2 \mathrm{eV}$ clearly resolved. There is an additional low-intensity, low-BE component in the $\mathrm{N}$ 1s spectra, Fig. 4(b), obtained from $\mathrm{Al} / \mathrm{TiN} / \mathrm{Si}(001)$ due to organic contamination during air exposure. This assignment is supported by the fact that the intensity of this feature increases with increasing air exposure time.

\section{Stability of Al cap layers versus air-exposure time}

The stability of Al cap layers as a function of airexposure time determines the maximum time allowed for sample transfer between deposition and XPS systems. Here, we focus on the thinnest Al cap layer, $d_{\mathrm{Al}}=1.5 \mathrm{~nm}$, which provides the least XPS signal attenuation. $\mathrm{Al} / \mathrm{TiN} / \mathrm{Si}(001)$ multilayers are stored in laboratory air, $23^{\circ} \mathrm{C}$ and $40 \%$ relative humidity, for times ranging from 10 to $100000 \mathrm{~min}$. Figures 5(a)-5(e) show C 1s, Al 2p, O 1s, Ti 2p, and N 1s core-level spectra recorded after $t=10,100,1000,10000$, and $100000 \mathrm{~min}$ of air exposure. The most pronounced change with $t$ is observed in C $1 \mathrm{~s}$ spectra, which contain three peaks centered at $282.1,285.6$, and $289.9 \mathrm{eV}$, corresponding to the chemical bonding states $\mathrm{C}-\mathrm{Al}, \mathrm{C}-\mathrm{C}$, and $\mathrm{C}=\mathrm{O} \quad($ and/or $\mathrm{O}-\mathrm{C}=\mathrm{O}){ }^{50,52}$ The intensities of the two higher-energy peaks increase with storage time indicating continuous accumulation of adventitious carbon on the surface, while the lower-energy peak, due to interactions at the $\mathrm{C} / \mathrm{Al}$ interface, remains unchanged. The $\mathrm{Al} 2 \mathrm{p}$ spectra exhibits a single Al-oxide peak at $75.1 \mathrm{eV}$, with no metallic feature, which does not change in intensity or shape as a function of air exposure time, indicating that 1.5 -nm-thick 

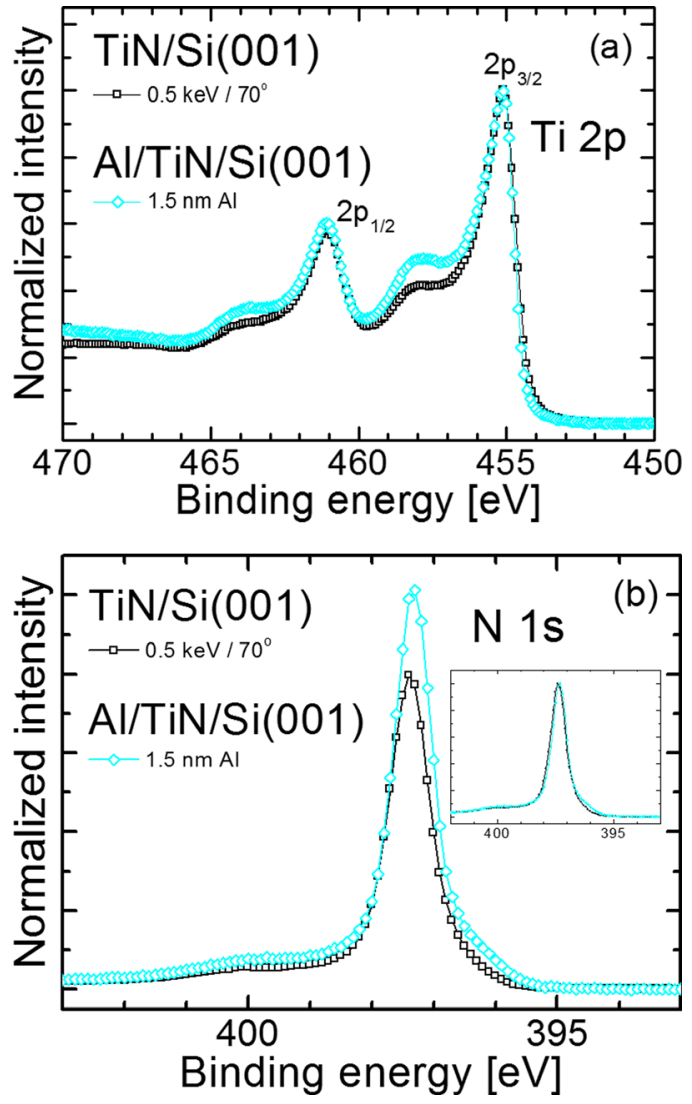

FIG. 4. (Color online) XPS (a) Ti 2p and (b) N 1s spectra from uncapped airexposed for $\leq 10 \mathrm{~min}$ polycrystalline $\mathrm{TiN} / \mathrm{Si}(001)$ samples ion-etched with $E_{\mathrm{Ar}^{+}}=0.5 \mathrm{keV}$ and $\psi=70^{\circ}$ compared to an air-exposed, but unetched, $\mathrm{Al} / \mathrm{TiN} / \mathrm{Si}(001)$ sample with a 1.5 -nm-thick Al cap layer. To facilitate comparison, each Ti $2 \mathrm{p}$ spectrum is normalized to the highest intensity peak (Ti $2 \mathrm{p}_{3 / 2}$ peaks at $455.2 \mathrm{eV}$ ); the corresponding $\mathrm{N}$ 1s spectra are scaled with the same factors. In order to highlight differences in peak shape, normalized $\mathrm{N}$ 1s spectra are shown in the inset in (b).

cap layers form a complete stable oxide in $\leq 10 \mathrm{~min}$ of air exposure. There is no indication of interfacial $\mathrm{Al} / \mathrm{TiN}$ interactions, even for the longest storage times. The only observable change in all other core level signals, Figs. 5(c)-5(e), is a small decrease in signal intensity with storage time due to the increased thickness of the carbon contamination layer; there is no evidence in time-dependent $\mathrm{O} 1 \mathrm{~s}$ spectra for the formation of Ti oxide or oxynitride.

\section{DISCUSSION}

Results shown in Fig. 1(a) for ion-etched uncapped air-exposed polycrystalline $\mathrm{TiN} / \mathrm{Si}(001)$ layers with no strong preferred orientation indicate that the Ti $2 \mathrm{p}$ satellite intensity decreases with increasing ion energy and ion penetration depth $\xi$. The corresponding set of $\mathrm{N} 1 \mathrm{~s}$ spectra in Fig. 1(b) reveals that upon Ar ion bombardment, both the primary and satellite peaks exhibit a decrease in intensity and the primary peak broadens on the low-BE side. The XPS-determined N/Ti ratios for all ion-etched air-exposed samples are significantly lower than the value obtained from RBS and ERDA analyses, even for the mildest set of ion etching conditions $\left(E_{\mathrm{Ar}^{+}}=0.5 \mathrm{keV}\right.$ and $\left.\psi=70^{\circ}\right)$ and decreases further with increasing ion penetration depth $\xi$. Similar effects were reported for epitaxial $\mathrm{TiN} / \mathrm{MgO}(001)$ films grown and ion-etched in-situ, with no air exposure, in an XPS system. ${ }^{48}$

The ion penetration depth $\xi$, which increases with increasing ion energy $E_{\mathrm{Ar}^{+}}$and decreasing ion incidence angle $\psi$, is characterized by the effective depth of collision cascade events, which can be estimated from Monte-Carlo based TRIM simulations of ion/surface interactions, and corresponds to the average TiN primary recoil projected range accounting for straggle. For Ti recoils, $\xi_{\mathrm{Ti}}=1.2 \mathrm{~nm}$ with $E_{\mathrm{Ar}^{+}}=0.5 \mathrm{keV}$ and $\psi=70^{\circ}$, and increases to 2.6, 4.0, and $5.3 \mathrm{~nm}$ with $E_{\mathrm{Ar}^{+}}=4 \mathrm{keV}$ and $\psi=70^{\circ}, 45^{\circ}$, and $0^{\circ}$. For $\mathrm{N}$ recoils, $\xi_{N}$ increases from 0.6 to $2.3,4.0$, and $5.3 \mathrm{~nm}$ for the same ion bombardment conditions. These length scales are comparable to typical XPS probing depths, which are controlled by electron inelastic mean free paths $\lambda$. The fraction of the XPS signal intensity $I_{d}$ originating from a surface layer of thickness $d$ is given by $[1-\exp (-d / \lambda)]$. With $\lambda=2.2 \mathrm{~nm}$ (for electrons in TiN with energy $E=1300 \mathrm{eV}$ ) (Ref. 53) and $d \sim \xi_{\mathrm{Ti}}$ (approximate width of ion-altered surface layer), the percentage contribution to the $\mathrm{Ti}$ and $\mathrm{N}$ core level XPS signal originating from the $\mathrm{Ar}^{+}$ion beam modified surface layer of thickness $d$ is $\sim 40 \%$ with $E_{\mathrm{Ar}^{+}}=0.5 \mathrm{keV}$ and $\psi=70^{\circ}$, and increases to $\sim 70, \sim 85$, and $\sim 90 \%$ with $E_{\mathrm{Ar}^{+}}=4 \mathrm{keV}$ and $\psi=70^{\circ}, 45^{\circ}$, and $0^{\circ}$. Thus, a significant fraction of the XPS signal arises from an ion-irradiation-altered TiN surface layer even for the mildest set of ion etching conditions used in these experiments and increases to essentially the entire sampling depth in the case of etching with $E_{\mathrm{Ar}^{+}}=4 \mathrm{keV} / \psi=0^{\circ}$. A serious ionirradiation effect is the loss of $\mathrm{N}$ due to preferential resputtering. For the mildest ion etch $\left(E_{\mathrm{Ar}^{+}}=0.5 \mathrm{keV} / \psi=70^{\circ}\right)$, i.e., lowest $\xi$, the XPS-determined N/Ti ratio is $0.74 \pm 0.03$, much lower than the actual value, $0.96 \pm 0.01$, obtained from RBS and ERDA. XPS N/Ti ratios decrease further to $0.68 \pm 0.03$ as $E_{\mathrm{Ar}^{+}}$is increased to $4 \mathrm{keV}$ and $\psi$ decreased to $0^{\circ}$.

The use of $\mathrm{Al}$ capping layers with thicknesses of 1.5-25.0 nm prevents TiN oxidation during sample air exposure as evident from the Ti $2 \mathrm{p}, \mathrm{N} 1 \mathrm{~s}$, and $\mathrm{O} 1 \mathrm{~s}$ spectra shown in Figs. 3(a), 3(b), and 3(d). Clean TiN spectral features are preserved, in particular, the Ti $2 \mathrm{p}$ and $\mathrm{N}$ 1s satellite features are intact, unlike the corresponding spectra from ion-etched air-exposed samples (see Fig. 1). There is no evidence in either the $\mathrm{Al} 2 \mathrm{p}$ or $\mathrm{N}$ 1s spectra indicating interfacial $\mathrm{Al} / \mathrm{TiN}$ reactions. This is consistent with TiN having a larger heat of formation $\left(\Delta_{f} H_{\mathrm{TiN}}^{0}=-3.5 \mathrm{eV} /\right.$ atom $)$ than $\mathrm{AlN}\left(\Delta_{f} H_{\mathrm{A} 1 \mathrm{~N}}^{0}\right.$ $=-3.3 \mathrm{eV} /$ atom $),{ }^{29}$ as well as with earlier studies which show that the $\mathrm{Al} / \mathrm{TiN}$ interface is stable up to $500^{\circ} \mathrm{C} ;{ }^{54-56}$ i.e., to a significantly higher temperature than used during $\mathrm{Al}$ deposition in the present experiments.

TiN oxidation during air exposure is prevented even by the thinnest $\mathrm{Al}$ capping layer, $d_{\mathrm{Al}}=1.5 \mathrm{~nm}$, indicating that the overlayer is continuous, in agreement with SEM images [see, for example, Fig. 2(a)] showing a smooth surface. The Al 2p core-level signal in Fig. 3(c) reveals that 1.5-nm-thick $\mathrm{Al}$ cap layers are completely oxidized, with no evidence of a 

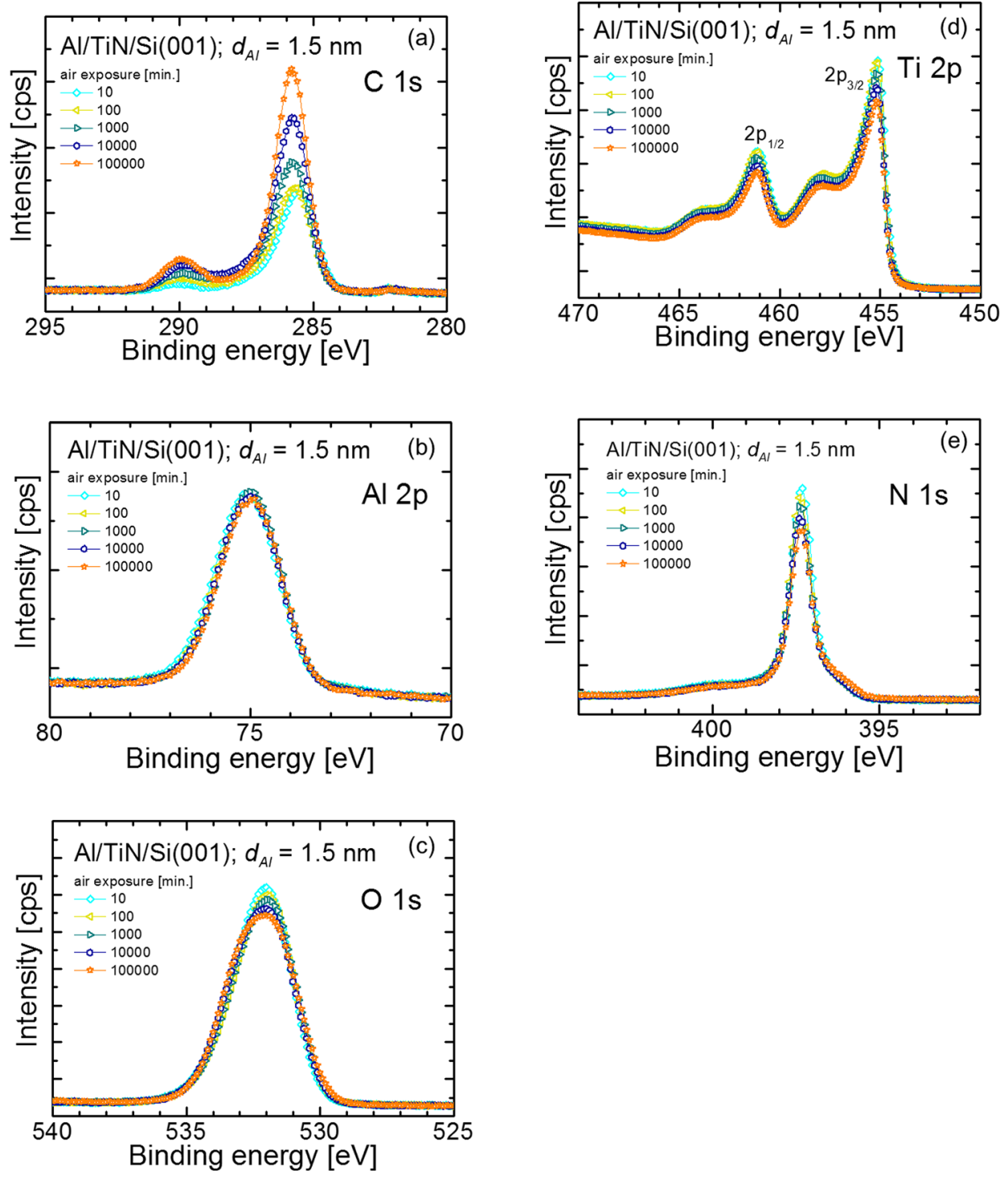

FIG. 5. (Color online) XPS (a) C 1s, (b) Al 2p, (c) O 1s, (d) Ti 2p, and (e) N 1s core-level spectra from air-exposed Al/TiN/Si(001) samples for which the Al cap layer thicknesses are $d_{\mathrm{Al}}=1.5 \mathrm{~nm}$. The spectra are recorded following $t=10,100,1000,10000$, and $100000 \mathrm{~min}$ of air exposure.

metallic $\mathrm{Al}$ peak. We estimate the thickness of the native $\mathrm{Al}$ oxide layer, based upon the intensity ratio of the $\mathrm{Al} 2 \mathrm{p}$ oxide to metal core level peaks ${ }^{57}$ acquired from the air-exposed $2-\mu$ m-thick Al film, to be $2.1 \mathrm{~nm}$. This is in very good agreement with the value, $2.2 \mathrm{~nm}$, we obtain by assuming that the $\mathrm{Al}$ and $\mathrm{Al}_{2} \mathrm{O}_{3}$ layers are fully dense such that $t_{\mathrm{ox}}=t_{\mathrm{Al}}\left(\rho_{\mathrm{Al}} M_{\mathrm{ox}}\right) /\left(\rho_{\mathrm{ox}} M_{\mathrm{Al}} N_{\mathrm{Al}}\right)$, in which $t$ is the layer thickness, $\rho$ is density, $M$ is the mass in amu, and $N_{\mathrm{Al}}=2$ is the number of $\mathrm{Al}$ atoms per oxide molecule.

Ti $2 p$ and $\mathrm{N}$ 1s peak intensities from $\mathrm{Al} / \mathrm{TiN} / \mathrm{Si}(001)$ samples decrease with increasing $\mathrm{Al}$ capping layer thickness $d_{\mathrm{Al}}$, due to inelastic electron scattering in the cap layer. However, the signal does not decay exponentially with increasing $d_{\mathrm{Al}}$, as would be expected in the case of attenuation by a continuous overlayer for which core-level intensity drops as $\sim \exp \left(-d_{\mathrm{Al}} / \lambda_{\mathrm{Al}}\right)$, in which $\lambda_{\mathrm{Al}}$ is the inelastic mean free path of Ti $2 \mathrm{p}$ and $\mathrm{N}$ 1s electrons in Al. This can be interpreted with the help of SEM images in Figs. 2(b)-2(d), which reveal significant surface roughness in samples with $6.0 \leq d_{\mathrm{Al}} \leq 25.0 \mathrm{~nm}$. Moreover, the roughness increases with increasing cap layer thickness, thus the average near-surface film density decreases. This accounts for the less-than-exponential decrease in Ti $2 \mathrm{p}$ and $\mathrm{N} 1 \mathrm{~s}$ core-level intensities with $d_{\mathrm{Al}}$.

Ion-etched air-exposed $\mathrm{TiN} / \mathrm{Si}(001)$ samples suffer from severe $\mathrm{N}$ loss resulting from preferential resputtering; the XPS-determined N/Ti values range from $0.74 \pm 0.03$ for the mildest etching conditions $\left(E_{\mathrm{Ar}^{+}}=0.5 \mathrm{keV}\right.$ and $\left.\psi=70^{\circ}\right)$ and decrease continuously to $0.68 \pm 0.03$ for the most severe $\mathrm{Ar}^{+}$ion etch $\left(E_{\mathrm{Ar}^{+}}=4 \mathrm{keV}\right.$ and $\left.\psi=0^{\circ}\right)$. In contrast, XPS $\mathrm{N} / \mathrm{Ti}$ ratio obtained from the Al-capped TiN samples is significantly higher, $0.98 \pm 0.03$, in very good agreement with RBS and ToF-ERDA results, $0.96 \pm 0.01$.

\section{CONCLUSIONS}

We show that thin metal layers provide effective barriers to sample oxidation and contamination during air exposure and allow subsequent quantitative XPS analyses in which 
ion etching is not required. Here, we use polycrystalline $\mathrm{TiN} / \mathrm{Si}(001)$ thin films as a model system and demonstrate that deposition of 1.5-nm-thick Al layers prior to air exposure allows nondestructive acquisition of high-resolution core-level spectra representative of clean samples, and hence, provide correct bonding assignments. The Ti $2 p$ and $\mathrm{N}$ 1s satellite features, which are sensitive to ion bombardment, exhibit high intensities comparable to those obtained from single-crystal $\mathrm{TiN} / \mathrm{MgO}(001)$ films grown and analyzed in-situ in a ultrahigh-vacuum XPS system; line shapes and peak energies are also in excellent agreement. There is no indication of reaction between the $\mathrm{Al}$ cap layers and the underlying TiN films, or for the formation of Ti oxide. XPS-determined N/Ti concentrations acquired from Al/TiN/ $\mathrm{Si}(001)$ samples agree very well with results obtained by Rutherford backscattering and elastic recoil analyses. In contrast, XPS-determined N/Ti ratios of air-exposed uncapped $\mathrm{TiN} / \mathrm{Si}(001)$ samples subjected to ion etching to remove oxides and adventitious contamination exhibit clear evidence of strong preferential $\mathrm{N}$ loss, which increases with increasing $\mathrm{Ar}$ ion energy and decreasing incidence angle.

Al $2 p$ core-level spectra from air-exposed Al/TiN/ $\mathrm{Si}(001)$ samples reveal that 1.5 -nm-thick Al cap layers are immediately fully oxidized with no evidence of a metallic Al XPS peak. However, XPS cap layer spectra exhibit increasingly strong metallic $\mathrm{Al}$ peaks as $d_{\mathrm{Al}}$ is increased from 6 to $25 \mathrm{~nm}$. For all samples, irrespective of $d_{\mathrm{Al}}$, there is no $\mathrm{Al} 2 \mathrm{p}$ or $\mathrm{N}$ 1s spectral indication of $\mathrm{AlN}_{\mathrm{x}}$ formation. Moreover, the intensities and shapes of the Ti $2 p$ and $\mathrm{N} 1$ s core level signals from TiN do not change following long-term (up to 70 days) sample exposure to ambient conditions prior to analysis showing that the thin $\mathrm{Al}$ cap layers provide stable surface passivation without spallation.

The metal cap-layer strategy for eliminating ion etching of air-exposed samples prior to quantitative XPS analyses, demonstrated here for $\mathrm{TiN} / \mathrm{Si}(001)$ thin films with an $\mathrm{Al}$ cap, can be applied to other material systems. The primary requirements for the choice of cap layer material are: (1) it should form a dense, continuous, and stable oxide (no spallation), (2) the cap should be thin to avoid significant signal attenuation from the underlying sample, (3) there should be no cap/sample interfacial reaction, and (4) core-level peaks from the cap layer should not overlap with those from the sample.

\section{ACKNOWLEDGMENTS}

Financial support from the European Research Council (ERC) through an Advanced Grant No. 227754, the VINN Excellence Center Functional Nanoscale Materials (FunMat) Grant No. 2005-02666, the Knut and Alice Wallenberg Foundation Grant No. 2011.0143, the Swedish Government Strategic Faculty Grant in Materials Science to Linköping University (SFO Mat-LiU AFM), and Swedish Research Council (VR) Project Grant No. 2014-5790 are gratefully acknowledged. Jens Jensen is acknowledged for carrying out the ERDA and RBS analyses.
${ }^{1}$ A. Hörling, L. Hultman, M. Odén, J. Sjölén, and L. Karlsson, Surf. Coat. Technol. 191, 384 (2005).

${ }^{2}$ P. H. Mayrhofer, C. Mitterer, L. Hultman, and H. Clemens, Prog. Mater. Sci. 51, 1032 (2006).

${ }^{3}$ H. Ljungcrantz, M. Odén, L. Hultman, J. E. Greene, and J.-E. Sundgren, J. Appl. Phys. 80, 6725 (1996).

${ }^{4}$ C.-S. Shin, D. Gall, N. Hellgren, J. Patscheider, I. Petrov, and J. E. Greene, J. Appl. Phys. 93, 6025 (2003).

${ }^{5}$ D. McIntyre, J. E. Greene, G. Hakansson, J.-E. Sundgren, and W.-D. Münz, J. Appl. Phys. 67, 1542 (1990).

${ }^{6}$ L. A. Donohue, I. J. Smith, W.-D. Münz, I. Petrov, and J. E. Greene, Surf. Coat. Technol. 94/95, 226 (1997).

${ }^{7}$ A. Ingason, F. Magnus, J. S. Agustsson, S. Olafsson, and J. T. Gudmundsson, Thin Solid Films 517, 6731 (2009).

${ }^{8}$ D. Gall, I. Petrov, and J. E. Greene, J. Appl. Phys. 89, 401 (2001).

${ }^{9}$ A. B. Mei, A. Rockett, L. Hultman, I. Petrov, and J. E. Greene, J. Appl. Phys. 114, 193708 (2013).

${ }^{10}$ C.-S. Shin, D. Gall, Y.-W. Kim, P. Desjardins, I. Petrov, J. E. Greene, M. Odén, and L. Hultman, J. Appl. Phys. 90, 2879 (2001).

${ }^{11}$ H.-S. Seo, T.-Y. Lee, I. Petrov, J. E. Greene, and D. Gall, J. Appl. Phys. 97, 083521 (2005).

${ }^{12}$ O. Knotek, M. Böhmer, and T. Leyendecker, J. Vac. Sci. Technol. A 4, 2695 (1986)

${ }^{13}$ T. Leyendecker, O. Lemmer, S. Esser, and J. Ebberink, Surf. Coat. Technol. 48, 175 (1991).

${ }^{14}$ J. M. Molarius, A. S. Korhonen, E. Harju, and R. Lappalainen, Surf. Coat. Technol. 33, 117 (1987).

${ }^{15}$ V. R. Parameswaran, J.-P. Immarigeon, and D. Nagy, Surf. Coat. Technol. 52, 251 (1992).

${ }^{16}$ M.-A. Nicolet, Thin Solid Films 52, 415 (1978).

${ }^{17}$ I. Petrov, E. Mojab, F. Adibi, J. E. Greene, L. Hultman, and J.-E. Sundgren, J. Vac. Sci. Technol. A 11, 11 (1993).

${ }^{18}$ J. S. Chun, I. Petrov, and J. E. Greene, J. Appl. Phys. 86, 3633 (1999).

${ }^{19}$ J. S. Chun, P. Desjardins, I. Petrov, J. E. Greene, C. Lavoie, and C. Cabral, Jr., Thin Solid Films 391, 69 (2001).

${ }^{20}$ J. S. Chun, P. Desjardins, C. Lavoie, C.-S. Shin, C. Cabral, Jr., I. Petrov, and J. E. Greene, J. Appl. Phys. 89, 7841 (2001).

${ }^{21}$ B. Subramanian, C. V. Muraleedharan, R. Ananthakumar, and M. Jayachandran, Surf. Coat. Technol. 205, 5014 (2011).

${ }^{22}$ J.-E. Sundgren, B.-O. Johansson, A. Rockett, S. A. Barnett, and J. E. Greene, in Physics and Chemistry of Protective Coatings, edited by J. E. Greene, W. D. Sproul, and J. A. Thornton (American Institute of Physics, New York, 1986), Ser. 149, p. 95.

${ }^{23}$ T. Lee, K. Ohmori, C.-S. Shin, D. G. Cahill, I. Petrov, and J. E. Greene, Phys. Rev. B 71, 144106 (2005).

${ }^{24}$ C.-S. Shin, S. Rudenja, D. Gall, N. Hellgren, T.-Y. Lee, I. Petrov, and J. E. Greene, J. Appl. Phys. 95, 356 (2004).

${ }^{25}$ D. Gall, R. Haasch, N. Finnegan, T.-Y. Lee, C.-S. Shin, E. Sammann, J. E. Greene, and I. Petrov, Surf. Sci. Spectra 7, 167 (2000).

${ }^{26}$ B. Kramer, G. Tomasch, M. Ray, J. E. Greene, L. Salvati, and T. L. Barr, J. Vac. Sci. Technol. A 6, 1572 (1988).

${ }^{27}$ B. Kramer, G. Tomasch, J. E. Greene, L. Salvati, T. L. Barr, and M. Ray, Phys. Rev. B: Condens. Matter Mater. Phys. 46, 1372 (1992).

${ }^{28}$ L. Gan, R. D. Gomez, C. J. Powell, R. D. McMichael, P. J. Chen, and W. F. Egelhoff, Jr., J. Appl. Phys. 93, 8731 (2003).

29"National Institute of Standards and Technology (NIST) Chemistry WebBook," see http://webbook.nist.gov/chemistry/, accessed 18 December 2014.

${ }^{30}$ L. Porte, L. Roux, and J. Hanus, Phys. Rev. B 28, 3214 (1983).

${ }^{31}$ I. Strydom and S. Hofmann, J. Electron Spectrosc. Relat. Phenom. 56, 85 (1991).

${ }^{32}$ J. Patscheider, N. Hellgren, R. T. Haasch, I. Petrov, and J. E. Greene, Phys. Rev. B 83, 125124 (2011).

${ }^{33}$ G. Greczynski, J. Jensen, J. E. Greene, I. Petrov, and L. Hultman, Surf. Sci. Spectra 21, 35 (2014).

${ }^{34}$ R. T. Haasch, T.-Y. Lee, D. Gall, J. E. Greene, and I. Petrov, Surf. Sci. Spectra 7, 193 (2000).

${ }^{35}$ G. Greczynski, J. Lu, M. Johansson, J. Jensen, I. Petrov, J. E. Greene, and L. Hultman, Surf. Coat. Technol. 206, 4202 (2012).

${ }^{36}$ G. Greczynski, J. Lu, M. Johansson, J. Jensen, I. Petrov, J. E. Greene, and L. Hultman, Vacuum 86, 1036 (2012).

${ }^{37}$ G. Greczynski et al., J. Vac. Sci. Technol. A 30, 061504 (2012). 
${ }^{38}$ G. Greczynski et al., Thin Solid Films 556, 87 (2014).

${ }^{39}$ G. Greczynski, J. Lu, I. Petrov, J. E. Greene, S. Bolz, W. Kölker, Ch. Schiffers, O. Lemmer, and L. Hultman, J. Vac. Sci. Technol. A 32, 041515 (2014).

${ }^{40}$ J. F. Moulder,W. F. Stickle, P. E. Sobol, and K. D. Bomben, Handbook of $X$-ray Photoelectron Spectroscopy (Perkin-Elmer Corporation, Eden Prairie, MN, 1992).

${ }^{41}$ D. A. Shirley, Phys. Rev. B 5, 4709 (1972).

${ }^{42}$ Kratos Analytical Ltd., Library filename: casaXPS_KratosAxisF1s.lib.

${ }^{43}$ J. F. Ziegler, J. P. Biersack, and U. Littmark, The Stopping and Range of Ions in Solids, Stopping and Ranges of Ions in Matter Vol. 1 (Pergamon, New York, 1984).

44"“Particle interactions with matter," www.srim.org, accessed 28 June 2013.

${ }^{45}$ A. Arranz and C. Palacio, Surf. Sci. 600, 2510 (2006).

${ }^{46}$ I. Bertoti, M. Mohai, J. L. Sullivan, and S. O. Saied, Surf. Interface Anal. 21, 467 (1994).

${ }^{47}$ D. Jaeger and J. Patscheider, J. Electron Spectrosc. Relat. Phenom. 185, 523 (2012).

${ }^{48}$ R. T. Haasch, T.-Y. Lee, D. Gall, J. E. Greene, and I. Petrov, Surf. Sci. Spectra 7, 204 (2000).

${ }^{49}$ P. Prieto and R. E. Kirby, J. Vac. Sci. Technol. A 13, 2819 (1995).

${ }^{50}$ A. V. Naumkin, A. Kraut-Vass, S. W. Gaarenstroom, and C. J. Powell,

"National Institute of Standards and Technology (NIST), X-ray photoelectron spectroscopy database," version 4.1, http://srdata.nist.gov/ xps/, accessed 17 December 2014.

${ }^{51}$ B. M. Biwer and S. L. Bernasek, J. Electron Spectrosc. Relat. Phenom. 40, 339 (1986).

${ }^{52}$ See Appendix E in Surface Analysis by Auger and X-ray Photoelectron Spectroscopy, edited by D. Briggs and J. T. Grant (IM Publications and Surface Spectra Limited, UK, 2003).

${ }^{53}$ The electron mean free path in TiN $\lambda=2.2 \mathrm{~nm}$ is determined based upon a separate set of experiments in which TiN/ZrN/Si(001) samples with TiN thicknesses varying from 0 to $20 \mathrm{~nm}$ are analysed. $\lambda$ is estimated from the attenuation of the $\mathrm{Zr} 3 \mathrm{~d}$ core level signal $(\mathrm{BE}=180 \mathrm{eV})$ excited with $\mathrm{Al} \mathrm{K} \alpha$ X-rays $(h \nu=1486.6 \mathrm{eV})$, resulting in an electron kinetic energy $E_{e} \sim 1300$ eV. $E_{e}$ is lower for Ti $2 \mathrm{p}$ and N 1s electrons (1030 and $1080 \mathrm{eV}$, respectively) and the corresponding mean free paths are somewhat shorter than $2.2 \mathrm{~nm}$, thus estimates of the percentage contributions to Ti $2 p$ and $N$ 1s core-level XPS signals from the $\mathrm{Ar}^{+}$ion beam altered surface layer are lower limits.

${ }^{54}$ L. Hultman, S. Benhenda, G. Radnoczi, J.-E. Sundgren, J. E. Greene, and I. Petrov, Thin Soild Films 215, 152 (1992).

${ }^{55}$ I. Petrov, E. Mojab, R. C. Powell, J. E. Greene, L. Hultman, and J.-E. Sundgren, Appl. Phys. Lett. 60, 2491 (1992).

${ }^{56}$ J.-S. Chun, J. R. A. Carlsson, P. Desjardins, D. B. Bergstrom, I. Petrov, J. E. Greene, C. Lavoie, C. Cabral, Jr., and L. Hultman, J. Vac. Sci. Technol. A 19, 182 (2001).

${ }^{57}$ B. R. Strohmeier, Surf. Interface Anal. 15, 51 (1990). 